\title{
Effects of capture surface morphology on feeding success of scyphomedusae: a comparative study
}

\author{
Nicholas Bezio ${ }^{1}$, John H. Costello ${ }^{2,3}$, Elijah Perry ${ }^{4}$, Sean P. Colin ${ }^{1,3, *}$ \\ ${ }^{1}$ Marine Biology, Roger Williams University, Bristol, RI 02809, USA \\ ${ }^{2}$ Biology Department, Providence College, Providence, RI 02918, USA \\ ${ }^{3}$ Eugene Bell Center, Marine Biological Laboratories, Woods Hole, MA 02543, USA \\ ${ }^{4}$ Environmental Science, Rhode Island University, South Kingstown, RI 02881, USA
}

\begin{abstract}
Predation by feeding-current foraging medusae can have detrimental effects on prey populations. Understanding the mechanics that control prey selection and ingestion rates with different types of prey enables us to better predict the predatory impact of these medusae. We quantified the outcomes of each post-entrainment stage of the feeding process in multiple scyphozoan jellyfish species to understand how post-entrainment feeding events influence feeding patterns. Using 3-dimensional video, we observed and quantified the fate of both passive and actively swimming prey that were entrained in the feeding current of 5 different scyphomedusan species belonging to the orders Semaeostomeae and Rhizostomeae. Less than $65 \%$ of entrained prey contacted the capture surfaces (termed contact efficiency) of the semaeostome medusae, while the rhizostome medusae came into contact with less than $35 \%$ of the prey entrained in the feeding current. However, when contacted, prey were very likely to be ingested (>90\%) by all species examined. These results suggest that prey capture by oblate medusae appears to be largely limited by the probability that prey entrained in the feeding current will contact a capture surface. As a passive process, this contact stage of the feeding process is directly affected by the morphology of the contact surfaces. The importance of the contact stage of the feeding process suggests that differences in prey selection patterns observed among oblate medusan taxa are likely dominated by the morphology of contact surfaces as opposed to traits which influence the other stages of the feeding process, i.e. bell shape and nematocysts.
\end{abstract}

KEY WORDS: Predator-prey interactions $\cdot$ Prey selection $\cdot$ Mechanistic ecology $\cdot$ Post-encounter

\section{INTRODUCTION}

Understanding scyphozoan jellyfish predation patterns and behaviors has gained importance due to increases in population sizes of jellyfish over recent years (Purcell et al. 2007). Some scyphozoan populations have expanded their ecosystem boundaries in response to ecosystem disturbances, such as overfishing (Utne-Palm et al. 2010), and are forming more frequent and massive blooms. Consequently, some of these scyphomedusan populations may be able to out-compete zooplanktivorous fish (Richardson et al. 2009). Our ability to understand and pre-

*Corresponding author: scolin@rwu.edu dict impacts of jellyfish populations on local marine communities largely depends upon our understanding of the mechanics which govern their predatory impact.

Some scyphomedusae, e.g. Periphylla periphylla, Catostylus mosaicus, and Nemopilema nomurai (Dong et al. 2010, Uye 2014), have been shown to have significant negative impacts on prey standing stocks and biodiversity (Behrends \& Schneider 1995, Graham et al. 2014). Zooplankton most influenced by these significant scyphozoan blooms include hydromedusae (Matsakis \& Conover 1991), decapod larvae (Sullivan et al. 1994), ciliates (Stoecker et al. 1987), 
and fish eggs/larvae (Titelman \& Hansson 2006). In cases where scyphomedusan predation is important, their predatory success has been attributed to factors including their high population densities, their inflated gelatinous bodies, and feeding currents which result in high encounter rates (Acuña et al. 2011, Pitt et al. 2013, Gemmell et al. 2015). Most studies aiming to understand medusan feeding have focused primarily on the pre-encounter (for scyphomedusae, an encounter is initiated when prey are entrained in the feeding current) capture process, e.g. feedingcurrent mechanics (Dabiri et al. 2005), or the end result of the feeding process, e.g. clearance rates (Matsakis \& Conover 1991, Ford et al. 1997, Brodeur et al. 2002, Titelman \& Hansson 2006) and prey capture maps (Ford et al. 1997, Nagata et al. 2016). From these studies we know that the feeding currents of scyphomedusae provide medusae with high encounter rates with surrounding prey but that clearance rates are considerably lower than encounter rates. With the exception of Suchman \& Sullivan (1998, 2000), few studies have quantified postencounter/entrainment capture processes associated with the feeding surfaces of medusae. This lack of information is most likely the result of the inherent difficulties associated with quantifying such capture processes. One consequence is the potential to overestimate prey capture rates, especially for larger adult stages.

Scyphomedusae include 2 major orders, Semaeostomeae and Rhizostomeae. Both use similar feeding currents to entrain prey but differ considerably in their feeding patterns and prey selection. Semaeostomes, such as Aurelia aurita, possess 4 distinct oral arms with tentacles around the bell margin. Semaeostomes have diverse diets consisting primarily of mesozooplankton and macrozooplankton (Båmstedt et al. 1994, Behrends \& Schneider 1995, Brodeur et al. 1999). In contrast, Rhizostomeae, such as Phyllorhiza punctata, have 8 oral arms fused to make up an oral disk, no tentacles, are limited mainly to tropical seas, and feed primarily on microplankton (Dawson et al. 2005, Peach \& Pitt 2005, Pierce 2005). These differences in feeding patterns presumably derive from the different capture surface morphology between semaeostomes and rhizostomes, which interact differently with feeding currents and contribute to different prey encounter and capture patterns.
By comparing morphologies and post-encounter feeding processes, our intent was to evaluate the importance of post-encounter events in determining prey selection and how medusan morphology contributes to different feeding patterns. Several scyphomedusae were examined to represent both semaeostomes (Aurelia aurita Linnaeus, 1758, Chrysaora plocamia Lesson, 1830) and rhizostomes (Cassiopea xamachana Bigelow, 1892, Catostylus tagi Haeckel, 1869, Phyllorhiza punctata Lendenfeld, 1884). Using 3-dimensional (3D) video observations we quantified the outcome of each stage of the feeding process of the medusae fed both Acartia hudsonica and Artemia $\mathrm{sp}$. These data were used to establish the role of each stage of the feeding process in determining predatory patterns.

\section{MATERIALS AND METHODS}

\section{Medusae collection and care}

Medusae including Aurelia aurita ( $\mathrm{N}=12)$, Chrysaora plocamia $(\mathrm{N}=7)$, Cassiopea xamachana $(\mathrm{N}=$ 7), Catostylus tagi $(\mathrm{N}=7)$, and Phyllorhiza punctata $(\mathrm{N}=7)$ were supplied by the New England Aquarium, Boston, Massachusetts, USA (Table 1). All medusae were housed in 371 closed system kreisel aquariums with $12 \mathrm{~h}$ light:12 h dark cycles under varying temperatures: A. aurita at $18^{\circ} \mathrm{C}$, C. plocamia at $10^{\circ} \mathrm{C}, \mathrm{C}$. xamachana at 25 to $28^{\circ} \mathrm{C}$, and C. tagi and P. punctata at $25^{\circ} \mathrm{C}$. Experiments were conducted either at Roger Williams University, Rhode Island, or the Marine and Biological Laboratory, Massachusetts. All medusae were starved for 1 to $2 \mathrm{~d}$ (depending on species) before feeding trials.

Table 1. Summary of the scyphomedusae used in this experiment including; (D) averaged bell diameter, (F) average medusae fineness, (T) average tentacle length, $(\mathrm{O})$ average oral arm length. Values are $\pm \mathrm{SD}$

\begin{tabular}{|lcccc|}
\hline \multirow{2}{*}{ Species } & \multicolumn{4}{c}{ Body dimensions $(\mathrm{cm})$} \\
\cline { 2 - 5 } & $\mathrm{D}$ & $\mathrm{F}$ & $\mathrm{T}$ & $\mathrm{O}$ \\
\hline $\begin{array}{l}\text { Aurelia aurita } \\
(\mathrm{N}=12)\end{array}$ & $2.03 \pm 0.40$ & $1.33 \pm 0.10$ & $0.51 \pm 0.09$ & $2.52 \pm 0.20$ \\
$\begin{array}{l}\text { Chrysaora plocamia } \\
(\mathrm{N}=7)\end{array}$ & $3.56 \pm 0.75$ & $3.49 \pm 0.20$ & $8.12 \pm 0.10$ & $7.11 \pm 0.41$ \\
$\begin{array}{l}\text { Cassiopea xamachana } \\
(\mathrm{N}=7)\end{array}$ & $2.54 \pm 1.20$ & $3.33 \pm 0.15$ & $0.50 \pm 0.10$ \\
$\begin{array}{l}\text { Catostylus tagi } \\
(\mathrm{N}=7)\end{array}$ & $1.27 \pm 0.30$ & $1.54 \pm 0.10$ & $3.04 \pm 0.12$ \\
$\begin{array}{l}\text { Phyllorhiza punctata } \\
(\mathrm{N}=7)\end{array}$ & $1.77 \pm 0.20$ & $1.25 \pm 0.10$ & $2.03 \pm 0.53$ \\
\hline
\end{tabular}




\section{Video recording}

A 3D video setup was used to accurately identify when prey were entrained in the feeding current and the location around the medusae where entrainment occurred. To get a 3D view of the interaction, medusae were placed in a right-triangle shaped filming vessel $(21 \times 15 \times 15 \mathrm{~cm})$ with the hypotenuse side constructed out of a mirror (Fig. 1; Colin et al. 2015). A cold, collimated LED light source was placed perpendicular to the camera. The light entering the filming vessel created a silhouette of the medusa and its reflection. Both of these were recorded simultaneously using a video camera (SONY HVR-77U Digital HD Video Camera Recorder, 30 frames per second) equipped with a standard lens (50 mm Nikon). A ruler was placed in the field of view of each recording to determine the spatial scale.

Individual medusae were tethered in the center of the filming vessel with a glass micro-sampling pipet $(25 \mu \mathrm{m})$, attached to the uppermost part of the exumbrella of the medusa using aquarium-safe super glue (Corrales-Ugalde et al. 2017). For each individual, video recording commenced after 5 to $20 \mathrm{~min}$ when 'normal' swimming behavior was observed. Live prey of either cultured Artemia sp. nauplii (0.6 mm, 1 to $2 \mathrm{~d}$ ) or wild Acartia hudsonica (male/ female ranging from 0.9 to $1.1 \mathrm{~mm}$ ) were introduced into the filming vessel in high enough concentration to initiate medusan feeding $\left(\sim 0.5 \mathrm{ml}^{-1}\right)$. Each feeding medusa was recorded individually for 30 to $45 \mathrm{~min}$. Recordings of medusae were stored and observed on

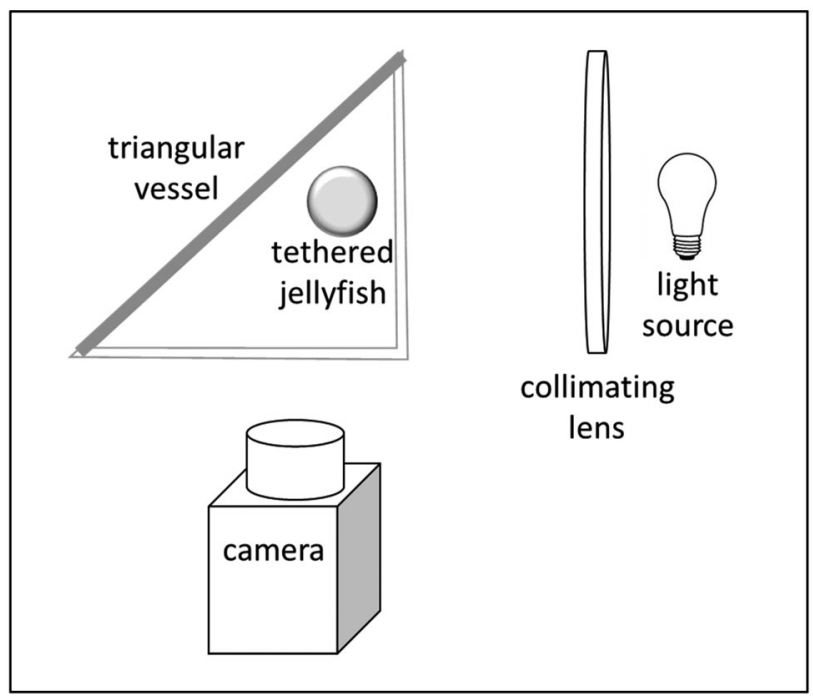

Fig. 1. Schematic of 3-dimensional video set-up. The tethered medusae were placed into the right-triangle shaped filming vessel $(21 \times 15 \times 15 \mathrm{~cm})$ with the hypotenuse side constructed out of a mirror
Vegas Pro (version 13.0, 64 bit), where entire video sequences were examined and predator-prey interactions were quantified.

\section{Data analysis}

To quantify prey capture and encounters with the feeding structures, we recorded the outcome of each stage of the feeding process (Fig. 2). Since medusae are not visual predators and they use a feeding current to encounter their prey, we define an encounter as occurring when a prey item is clearly entrained (being transported) by the feeding current of the medusae. Consequently, we will use the term 'entrainment' throughout the rest of the manuscript to denote an encounter. The definition for feeding efficiency has been variously defined by previous authors, so for this study we defined different feeding efficiencies based on 3 sequential steps (Fig. 2): contact (Eq. 1), capture (Eq. 2), and retention (Eq. 3). For this experiment we defined contact efficiency as the proportion of entrained prey particles that made contact with the feeding structures of the medusae. Capture efficiency was the proportion of contacted prey that were captured, i.e. stuck to the capture surface. Retention efficiency was the proportion of entrained prey that were ultimately ingested. We did not track prey into the guts and assumed if they remained captured for $>30 \mathrm{~s}$ that they were eventually ingested.

$$
\begin{gathered}
\text { Contact efficiency } \\
=\text { no. prey contacted/ no. prey entrained } \times 100 \\
\text { Capture efficiency } \\
=\text { no. prey captured/ no. prey contacted } \times 100 \\
\text { Retention efficiency } \\
=\text { no. prey captured/ no. prey entrained } \times 100
\end{gathered}
$$

Capture maps were generated from the 3D videos. During video analysis, individual prey were tracked in relation to the medusae and the medusa's reflection to observe points of contact. Points of contact

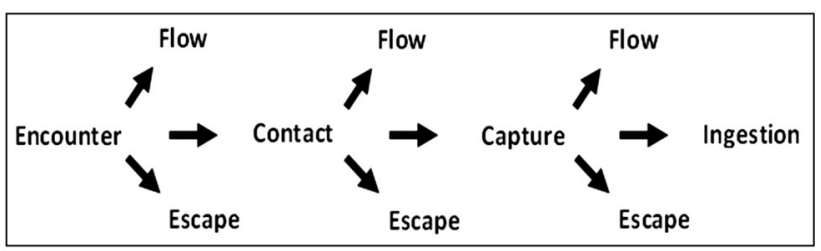

Fig. 2. Post-entrainment stages of the predator-prey interactions that occur during the feeding process. At each stage, prey may avoid capture by actively escaping or being passively transported away by flow 
were recorded on line maps generated by averaging the size ratios of the medusae using dimensions recorded in ImageJ (64 bit, Java 1.8.0_66).

\section{Nematocyst distribution and density}

Nematocysts were identified and recorded using a Nikon Eclipse TE2000-U inverted microscope equipped with a Fastcam mini UX50/100 camera. Nematocyst patterns were determined by observing the distribution and density at equal distances along the length of the feeding appendages. Nematocysts were identified based on their volume and extracellular morphology following procedures and methods described by Colin \& Costello (2007) and CorralesUgalde et al. (2017).

\section{Statistical analysis}

Statistical analyses were performed using Sigma Plot@ statistical software. Analysis of variance tests were performed to compare post-entrainment events among medusan species and prey type and nematocyst distributions. Between-group comparisons were made between the 5 medusan species and withingroup comparisons were made for the 2 prey types. Holm-Sidak tests were used to make post-hoc comparisons to compare efficiencies between the semaeostome and rhizostome species (significance level, $\alpha=0.05)$. All of the data conformed to the assumptions of homoscedasticity (Browne-Forsythe test) and normality (Shapiro-Wilk test).

\section{RESULTS}

\section{Feeding efficiencies of scyphomedusae}

Feeding efficiencies were quantified to determine the proficiency of morphologically distinct medusae in contacting, capturing and retaining prey that were entrained in their feeding current. Both species types (2-way ANOVA, $\left.F_{4,63}=65.0, \mathrm{p}<0.001\right)$ and prey type (2-way ANOVA, $\left.F_{2,63}=34.9, \mathrm{p}<0.001\right)$ affected contact efficiencies with no interaction $\left(F_{8,63}=2.0, \mathrm{p}>\right.$ 0.05; Fig. 3A). Post-hoc comparisons between each species type showed that all the semaeostome species contacted a significantly greater proportion of the prey entrained in their feeding current (contact efficiency) than did rhizostome species (Fig. 3A; HolmSidak post-hoc test, $\mathrm{p}<0.001)$. Specifically, mean se-
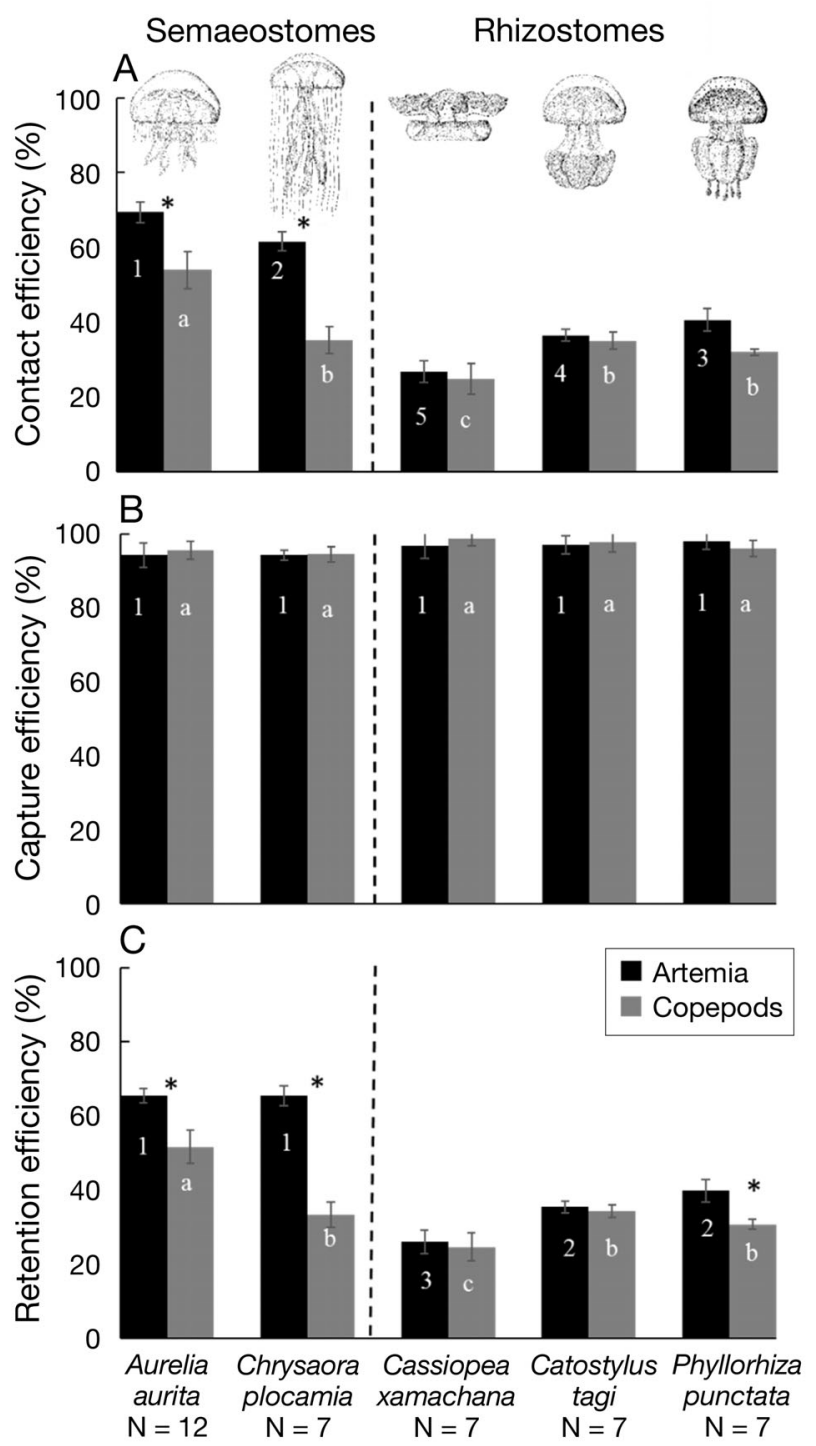

Fig. 3. Percent success of each stage of the post-entrainment feeding stages. (A) Contact, (B) capture, and (C) retention efficiencies for 5 species of Scyphozoa (Aurelia aurita, Chrysaora plocamia, Cassiopea xamachana, Catostylus tagi, and Phyllorhiza punctata) provided different types of prey, Artemia sp. or the copepod Acartia hudsonica. Asterisks indicate significant differences in efficiencies between prey types. Different numbers and letters indicate significant differences among medusa species for Artemia and copepod prey, respectively. Significance was based on Holm-Sidak post-hoc comparisons $(\mathrm{p}<0.05)$. Error bars are SD

maeostome contact efficiencies were $65 \%$ (Artemia prey) and $45 \%$ (copepod prey) compared to only $35 \%$ (Artemia prey) and 32\% (copepod prey) for the rhizostomes. Mobile prey such as Acartia hudsonica could actively avoid contact using evasive jumps and, as a result, entrained copepods contacted semaeostome medusae less than the non-evasive prey, Artemia sp. (Fig. 3A; Holm-Sidak post-hoc test, p < 0.001). 
Once contacted, neither prey type was successful at escaping and both were caught with high capture efficiencies ( $>90 \%$; Fig. 3B). As a result, most of the prey contacted were ultimately ingested, and this is reflected by retention efficiencies (which indicate the overall success of the encounter process) that were only slightly lower than contact efficiencies (Fig. 3C).

As mentioned, a lower proportion of entrained prey contacted the oral arms of rhizostome medusae and, consequently, contact efficiencies were lower for rhizostome than for semaeostome medusae (Fig. 3A). Prey that did contact the oral arms of the rhizostomes were typically captured, which resulted in high capture efficiencies (>95\%) that were similar to those of the semaeostomes (Fig. 3B). Prey escapes after contact were mainly the result of the feeding current dislodging prey. However, prey would often be recaptured shortly after the initial dislodgement. Because fewer prey were retained relative to those entrained, rhizostome medusae were characterized by lower overall retention efficiencies than semaeostome me- dusae (Fig. 3C). Specifically, the mean retention efficiencies among all the semaeostomes were $63 \%$ (Artemia prey) and $42 \%$ (copepod prey) compared to only $34 \%$ (Artemia prey) and $30 \%$ (copepod prey) for the rhizostomes. Of the tested rhizostomes, Cassiopea xamachana experienced the lowest contact and retention efficiency of all the medusan species. An overall comparison of contact, capture, and retention rates for both the semaeostome and the rhizostome medusae indicates that initial contact between the medusan capture surface and prey appears to be the rate-limiting step for prey selection and ingestion rates.

\section{Capture maps}

To compare the role of different capture surfaces in the encounter process, we constructed capture maps displaying the percentage of prey contacts over the length of the medusae (Fig. 4). Capture maps of

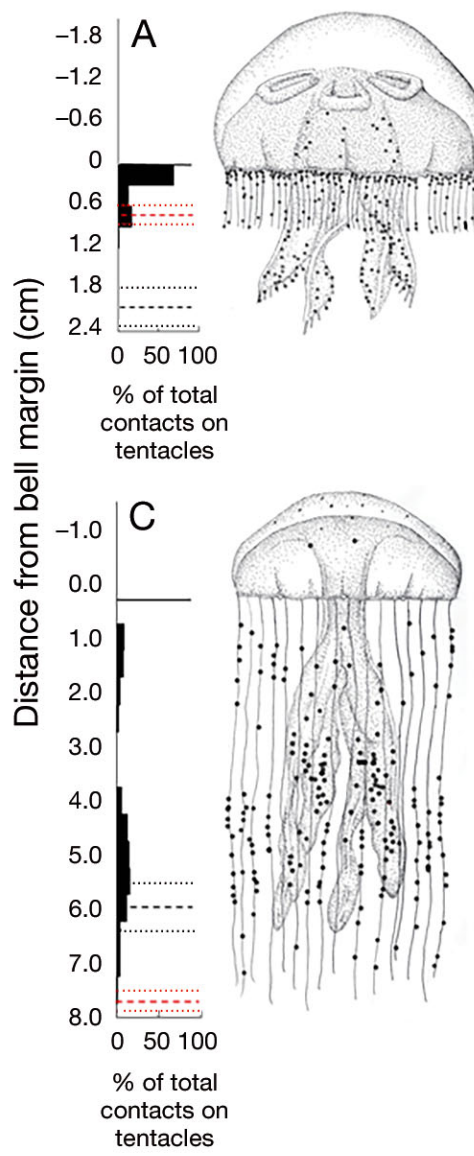

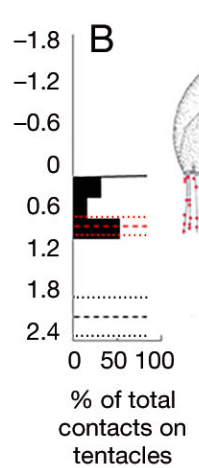
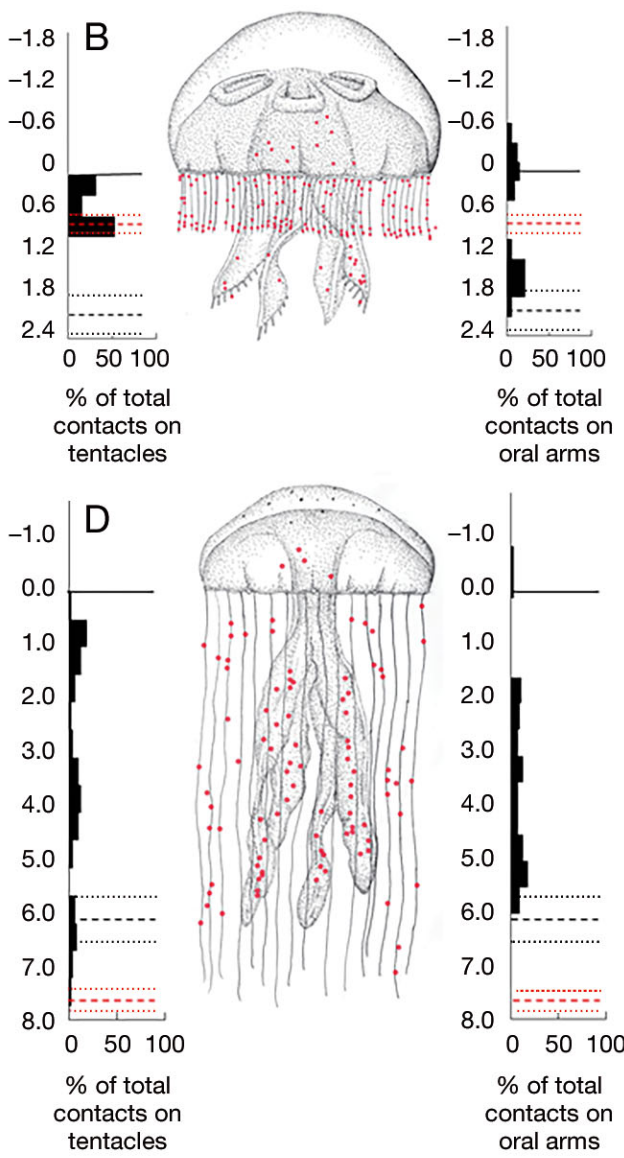

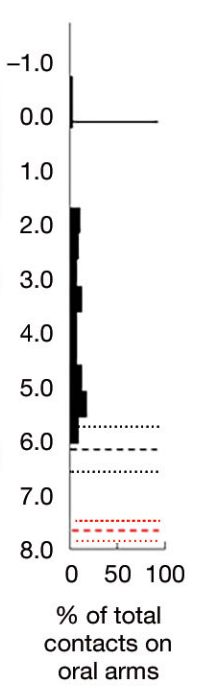

Fig. 4. Distribution of captures by the semaestomes $(A, B)$ Aurelia aurita $(N=12)$ and $(C, D)$ Chrysaora plocamia $(N=7)$ when exposed to (A,C) Artemia sp. (black dots) and (B,D) the copepod Acartia hudsonica (red dots). Bold lines: bell margin; black dashed lines: average oral arm length; black dotted lines: size variation of the oral arms; red dashed lines: average tentacle length; red dotted lines: size variation of the tentacles 
semaeostome medusae revealed that similar quantities of Artemia sp. were captured on both the tentacles (Aurelia aurita $\mathrm{n}=168$ captures, Chrysaora plocamia $\mathrm{n}=215$ captures) and the oral arms (A. aurita $\mathrm{n}=217, C$. plocamia $\mathrm{n}=223$ ), indicating no clear advantage of either capture surface. Likewise, Acartia hudsonica was captured similarly on either the tentacles (A. aurita $\mathrm{n}=202, C$. plocamia $\mathrm{n}=103$ ) or the oral arms (A. aurita $\mathrm{n}=222, C$. plocamia $\mathrm{n}=144$ ).

Capture maps revealed that $A$. aurita medusae caught the less responsive prey, Artemia sp., closer to the bell margin, while they caught faster-moving copepods further down the tentacles, closer to the tentacle tips (Fig. 4A,B). C. plocamia captured both
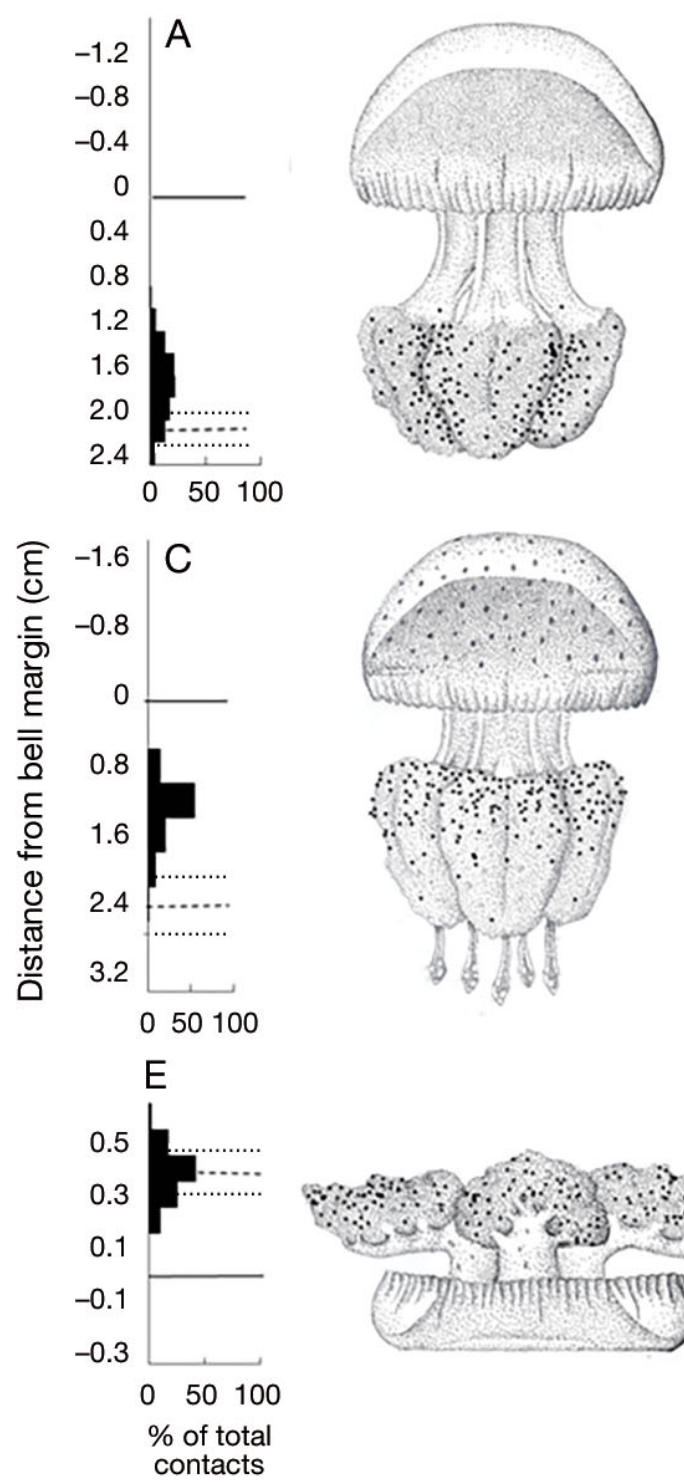

prey types in similar locations (Fig. 4C,D). Interestingly, captures for C. plocamia occurred in bands moving away from the bell margin where the prey clustered at specific distances. These clusters seemed to alternate between tentacles and oral arms (Fig. 4C,D). This could be the result of varying nematocyst distributions or patterns of how the wake transported prey to the surfaces.

Unlike the semaeostomes, the rhizostomes Catostylus tagi and Phyllorhiza punctata experienced horizontal variations in capture on the oral arms. C. tagi captured greater concentrations of prey on the edges of the external wings of the oral lobes where the feeding currents are most prevalent (Fig. 5A,B).
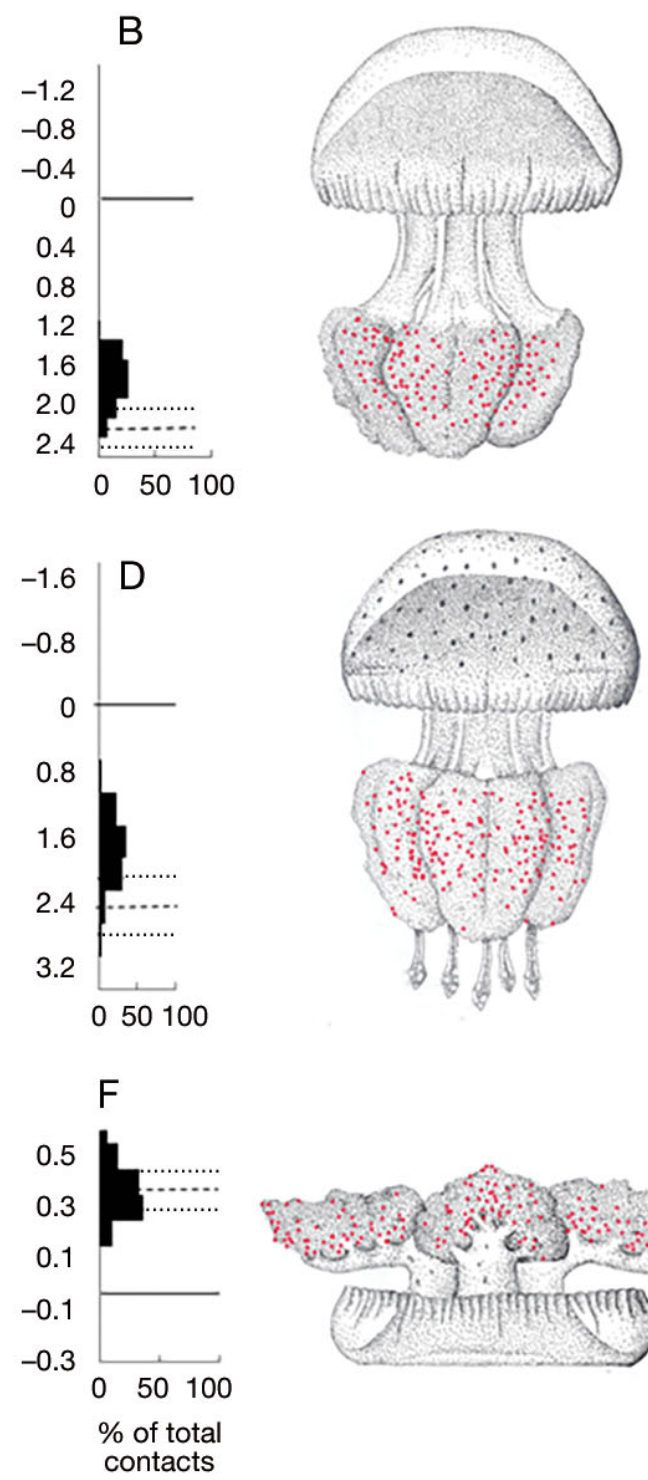

Fig. 5. Distribution of captures by the rhizostomes $(\mathrm{A}, \mathrm{B})$ Catostylus tagi $(\mathrm{N}=7),(\mathrm{C}, \mathrm{D})$ Phyllorhiza punctata $(\mathrm{N}=7)$ and $(\mathrm{E}, \mathrm{F})$ Cassiopea xamachana $(\mathrm{N}=7$ ) fed with $(\mathrm{A}, \mathrm{C}, \mathrm{E})$ Artemia sp. (black dots) and (B,D,F) the copepod Acartia hudsonica (red dots). Bold lines: bell margin; black dashed lines: average oral arm length; black dotted lines: size variation of the oral arms 

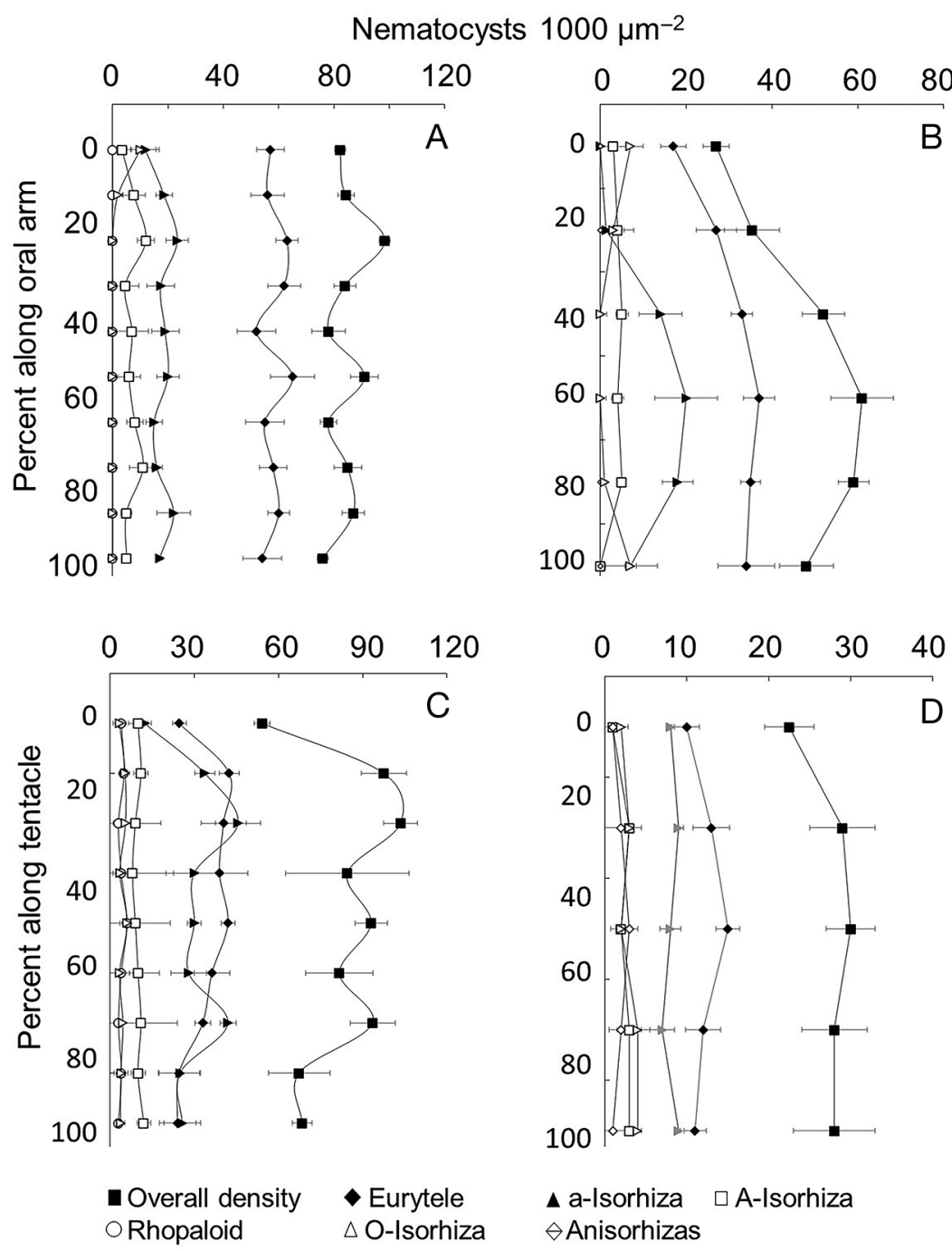

$\Delta$ a-Isorhiza $\square$ A-Isorhiza $\diamond$ Anisorhizas

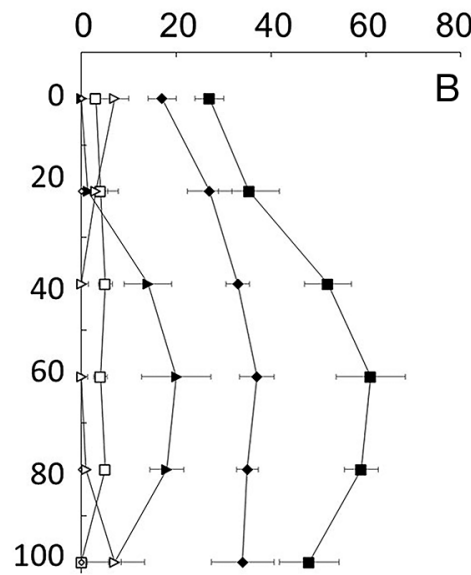

Fig. 6. The distribution and density of nematocysts on $(A, B)$ the oral arms and $(\mathrm{C}, \mathrm{D})$ tentacles of the semaeostomes $(\mathrm{A}, \mathrm{C})$ Chrysaora plocamia and $(\mathrm{B}, \mathrm{D})$ Aurelia aurita $(\mathrm{N}=3)$. Error bars represent standard deviations

aurita (ANOVA, $F_{4,26}=1.51, \mathrm{p}=0.23$ ) and C. plocamia (ANOVA, $F_{8,26}=$ 0.96, p > 0.4) did not change with distance from the bell.

Nematocyst types distributed along the length of the feeding appendages did not vary greatly in A. aurita, with only a greater abundance of aisorhiza near the tips of the oral arms (Fig. 6B). No pattern in the distribution of nematocysts could be seen in either the oral arms or tentacles of $C$. plocamia (Fig. 6A,C). Therefore, it is most likely that the patterns of capture locations for C. plocamia are the result of flow patterns rather than nematocyst distributions.

\section{DISCUSSION}

Understanding the mechanics of prey encounter and capture is fundamental to predicting the ecological role of predators because the feeding process determines which prey, and how many of them, are ingested. The feeding process can be broken down into multiple events where prey may avoid predation (either actively or passively) at each stage of the process (Fig. 2). For oblate feeding-current producing medusae, prey encounters are primarily initiated by prey entrainment within a feeding current followed by prey transport to medusan capture surfaces. Subsequent prey

$P$. punctata captured prey closer to the bell margin on top of the outer wings of the oral arms (Fig. 5C,D). For both medusae, prey were evenly captured along the length of the oral arms with zonation only occurring along the width of the structures. Capture maps of Cassiopea xamachana revealed no clear pattern in the distribution of captures on the feeding appendages for either prey (Fig. 5E,F).

\section{Nematocyst distribution and density}

Nematocyst densities were measured for the semaeostomes to determine whether nematocyst density patterns corresponded to prey capture patterns. The density of the nematocysts on the tentacles of $A$. capture depends upon contact of the entrained prey with capture surfaces and prey retention by nematocysts embedded within the capture surface. The entrainment-encounter process has been well studied and it is clear that oblate medusae process large fluid volumes, enabling high encounter and capture rates (Costello \& Colin 1994, 1995, Dabiri et al. 2005, Peng \& Dabiri 2008, Acuña et al. 2011, Katija et al. 2011, Santhanakrishnan et al. 2012). However, post-entrainment events are also important in determining prey selection (Suchman \& Sullivan 2000), yet few studies have quantified the post-entrainment success rates of oblate medusae. Our current study demonstrates that scyphozoan medusae capture and retain $\leq 63 \%$ prey transported past their capture surfaces. Captures appear to be most limited by the probability 
of entrained prey coming into contact with trailing capture surfaces (i.e. contact efficiency), but if contacted, prey are very likely to be retained and ingested (capture efficiency $>95 \%$ ). This has important implications on the predatory impact, prey selection and evolution of feeding-current foraging medusae.

\section{Determinates of prey selection}

Previous research on prey selection by feedingcurrent foraging medusae has held that prey selection is largely determined by prey escape speeds relative to the velocity of the medusan feeding current (Costello \& Colin 1994, 1995). Based on this notion, slow or non-swimming prey are more vulnerable to predation by oblate medusae because of their inability to escape from the feeding current (Costello \& Colin 1994, 1995). Consequently, oblate medusae largely select vulnerable prey such as eggs, fish larvae, and other gelatinous zooplankton (Purcell \& Grover 1990, Sullivan et al. 1994, Costello \& Colin 2002, Purcell \& Decker 2005). Consistent with this, our study showed that slow-swimming Artemia were more vulnerable to predation by the semaeostomes than fast-swimming copepods. However, there are important inconsistencies with the entrainmentdominated prey selection model. For example, fastswimming adult copepods are often consumed by oblate medusae (Sullivan et al. 1994, Suchman \& Sullivan 1998) and are, in fact, more vulnerable to predation than smaller, slower nauplii and copepodites (Purcell 1992, Sullivan et al. 1994, Suchman \& Sullivan 1998, Hansson 2006). Small prey, such as juvenile copepod stages and bivalve veliger larvae, are readily entrained in the feeding current of medusae but generally pass through the tentacles and oral arms of the medusa without being contacted (Suchman \& Sullivan 1998, 2000). The latter prey selection studies suggest that although the feeding current of oblate medusae is highly effective at entraining a large variety of prey (even fast-escaping copepods; Suchman \& Sullivan 2000), post-entrainment events are perhaps more influential in determining prey selection (Suchman \& Sullivan 1998, 2000). Furthermore, the current study shows that of the postentrainment events, the contact stage is the greatest rate-limiting step. Therefore, of the different stages of the feeding process that influence prey selection, it appears that while entrainment and capture by nematocysts play a role in determining prey selection, they serve as less influential factors than the probability that prey will contact capture surfaces.
This is a revision to the conventional entrainmentdominated prey selection model (Costello \& Colin 1994, 1995) and helps explain in situ prey selection patterns. A contact-dominated model means that prey selection depends primarily on the probability that a contact occurs between entrained prey and capture surfaces. For semaeostome medusae, which have a relatively low density of capture surfaces (i.e. tentacles and oral arms) compared to rhizostome medusae, larger prey are more likely to contact capture surfaces than small prey (Madin 1988). As a result, studies have found that large gelatinous zooplankton, larvaceans, and fish eggs are more abundant in the guts of Chrysaora spp., Cyanea spp., Pelagia spp., and Phacellophora spp. (Fancett 1988, Purcell \& Sturdevant 2001, Suchman et al. 2008). But we still see large copepods in these medusan guts because if copepods are not able to escape entrainment, their larger size makes them vulnerable to capture and ingestion. Aurelia spp., which have more finely spaced tentacles lining the bell margin, have been shown to select mid-sized prey such as small copepods, while they do not readily capture the larger, fast copepods or small nauplii (Sullivan et al. 1994, Suchman \& Sullivan 1998, Graham \& Kroutil 2001, Purcell \& Sturdevant 2001). This suggests that the largest copepods avoid entrainment while smaller copepods and nauplii do not (Graham \& Kroutil 2001). However, of the prey entrained, the small copepods are more likely than nauplii to contact capture surfaces due to their larger size. Therefore, a contact-dominated prey selection model suggests that small changes to capture surface morphology can have large effects on prey selection.

\section{Evolutionary consequences}

The rate-limiting stage in the feeding process, the contact stage, is primarily determined by the size of the prey in relation to the capture surface morphology (Madin 1988). Interestingly, capture surface morphology is the least conserved trait among scyphomedusan taxa. In contrast, the traits that control entrainment and retention-bell shape and nematocysts, respectively-are highly conserved among scyphomedusae. The aspect ratio of scyphomedusan bells (fineness ratio) is the primary factor determining the feeding-current dynamics (Dabiri et al. 2005, 2010), and most scyphomedusae have very similarly shaped oblate bells with a fineness ratio of approximately $0.4 \pm 0.1$ (Costello et al. 2008). Similarly, the nematocyst complements of 29 species of 
scyphomedusae (those for which nematocysts have been identified) are all characterized by primarily the same 2 types of nematocysts, heterotrichous microbasic euryteles and holotrichous isorhizas. A third nematocyst type, heterotrichous anisorhizas, additionally occurs in many of the species (Weil 1934, Calder 1983). Bell pulsations by oblate bells are highly effective at initiating encounters, and nematocysts appear to be highly effective at retaining contacted prey. This may explain why these traits have been evolutionarily conserved.

Diversity in capture surface morphology enables different medusan taxa to exploit different niches by altering prey selection patterns. This is illustrated by the comparison between semaeostomes and rhizostomes. The tentacles and oral arms of semaeostome medusae are more effective at contacting and capturing larger prey. In contrast, rhizostomes primarily select and feed on small nauplii and veliger larvae (Larson 1991, Peach \& Pitt 2005, Álvarez-Tello et al. 2016). The prey used in our study, Artemia sp. and adult copepods, are much larger than those typically selected by rhizostomes (1 vs. $0.25 \mathrm{~mm}$ ). Consequently, we observed lower contact efficiencies for the rhizostomes than the semaeostomes (but similarly high capture efficiencies). This suggests that the digitata on the oral disk of rhizostomes are not as likely to contact entrained large prey as the tentacles of semaeostomes, and this difference alters prey selection patterns. However, a more detailed study tracking and quantifying the interactions of rhizostome capture surfaces with different-sized prey is required to better understand why digitata are more effective at capturing small rather than large prey. Nevertheless, it is the differences in capture surface morphology which explains the difference in prey selection patterns between semaeostomes and rhizostomes rather than bell shape and nematocyst complement.

\section{Passive feeding and trophic impact}

Medusae such as scyphozoans are often grouped with another predatory gelatinous group, the ctenophores. However, there are critical differences in the predation mechanics of the 2 groups that influence their community impact. The capture of entrained prey by feeding-current foraging medusae is a passive process determined by the probability that prey in the current will contact passively trailing capture surfaces. In contrast, the lobate ctenophore, Mnemiopsis leidyi, actively scans its feeding current using its sensory capabilities to detect and actively capture prey in its feeding current (Colin et al. 2015). Consequently, M. leidyi retains greater than $90 \%$ of the prey entrained in its feeding current (Waggett \& Costello 1999, Colin et al. 2015). By comparison, oblate medusae feed less efficiently, retaining less than $63 \%$ of the prey they entrain. Interestingly, oblate medusae retention efficiencies are more comparable to, and in many cases higher than, visual fish predators feeding on copepods (O'Brien et al. 1976, Swift 1981, Gemmell \& Buskey 2011). The feeding strategy of $M$. leidyi is based on generation of an undetectable, continuous feeding current that efficiently retains entrained prey (Costello \& Coverdale 1998, Costello et al. 1999, Waggett \& Costello 1999, Colin et al. 2010). This strategy relies on stealth. In contrast, the strategy of oblate medusae relies on a feeding current that bulk processes large volumes of fluid (Dabiri et al. 2005, Peng \& Dabiri 2008, Acuña et al. 2011, Katija et al. 2011). This strategy appears to rely on high encounter/entrainment rates offsetting lower retention efficiencies. In the end, both strategies result in high size-specific clearance rates (Acuña et al. 2011 and reference therein). However, sensory scanning appears to enable the lobate ctenophore $M$. leidyi to have a greater size-specific clearance rate, and consequent trophic impact, than oblate medusae (Colin et al. 2015). Nevertheless, when medusae abundances are sufficiently high, their passive capture mechanism is sufficient to enable oblate medusae to impact the standing stocks of prey species (Purcell \& Arai 2001, Costello et al. 2008 and reference therein).

\section{Conclusion}

Prey capture by oblate medusae appears to be largely limited by the probability that prey entrained in the feeding current will contact a capture surface. As a passive process, this contact stage of the feeding process will be directly affected by the morphology of the contact surface. Consequently, we find great diversity among oblate medusan taxa in the shape of contact surfaces, while traits which influence the other stages of the feeding process, bell shape and nematocysts, have remained relatively conserved in the evolution of scyphomedusae.

Acknowledgements. This work was funded by a NSF Biological Oceanography grant awarded to S.P.C. and J.H.C. (OCE 1536688) and supported by the Roger Williams University Foundation to Promote Teaching and Scholarship. 


\section{LITERATURE CITED}

Acuña JL, López-Urrutia A, Colin S (2011) Faking giants: the evolution of high prey clearance rates in jellyfishes. Science 333:1627-1629

Álvarez-Tello FJ, López-Martínez J, Lluch-Cota DB (2016) Trophic spectrum and feeding pattern of cannonball jellyfish Stomolophus meleagris (Agassiz, 1862) from central Gulf of California. J Mar Biol Assoc UK 96: 1217-1227

Båmstedt U, Martinussen M, Matsakis S (1994) Trophodynamics of the two scyphozoan jellyfishes, Aurelia aurita and Cyanea capillata, in western Norway. ICES J Mar Sci 51:369-382

Behrends G, Schneider G (1995) Impact of Aurelia aurita medusae (Cnidaria, Scyphozoa) on the standing stock and community composition of mesozooplankton in the Kiel Bight (western Baltic Sea). Mar Ecol Prog Ser 127: 39-45

Brodeur RD, Mills CE, Overland JE, Walters GE, Schumacher JD (1999) Evidence for a substantial increase in gelatinous zooplankton in the Bering Sea, with possible links to climate change. Fish Oceanogr 8:296-306

*Bodeur RD, Sugisaki H, Hunt GL Jr (2002) Increases in jellyfish biomass in the Bering Sea: implications for the ecosystem. Mar Ecol Prog Ser 233:89-103

* Calder DR (1983) Nematocysts of stages in the life cycle of Stomolophus meleagris, with keys to scyphistomae and ephyrae of some western Atlantic Scyphozoa. Can J Zool 61:1185-1192

Colin SP, Costello JH (2007) Functional characteristics of nematocysts found on the scyphomedusa Cyanea capillata. J Exp Mar Biol Ecol 351:114-120

Colin SP, Costello JH, Hansson LJ, Titelman J, Dabiri JO (2010) Stealth predation and the predatory success of the invasive ctenophore Mnemiopsis leidyi. Proc Natl Acad Sci USA 107:17223-17227

* Colin SP, MacPherson R, Gemmell B, Costello JH, Sutherland K, Jaspers C (2015) Elevating the predatory effect: sensory-scanning foraging strategy by the lobate ctenophore Mnemiopsis leidyi. Limnol Oceanogr 60:100-109

* Corrales-Ugalde M, Colin SP, Sutherland KR (2017) Nematocyst distribution corresponds to prey capture location in hydromedusae with different predation modes. Mar Ecol Prog Ser 568:101-110

* Costello JH, Colin SP (1994) Morphology, fluid motion and predation by the scyphomedusa Aurelia aurita. Mar Biol 121:327-334

Costello JH, Colin SP (1995) Flow and feeding by swimming scyphomedusae. Mar Biol 124:399-406

* Costello JH, Colin SP (2002) Prey resource use by coexistent hydromedusae from Friday Harbor, Washington. Limnol Oceanogr 47:934-942

Costello JH, Coverdale R (1998) Planktonic feeding and evolutionary significance of the lobate body plan within the ctenophora. Biol Bull 195:247-248

Costello JH, Loftus R, Waggett R (1999) Influence of prey detection on capture success for the ctenophore Mnemiopsis leidyi feeding upon adult Acartia tonsa and Oithona colcarva copepods. Mar Ecol Prog Ser 191:207-216

* Costello JH, Colin SP, Dabiri JO (2008) Medusan morphospace: phylogenetic constraints, biomechanical solutions, and ecological consequences. Invertebr Biol 127:265-290

Dabiri JO, Colin SP, Costello JH, Gharib M (2005) Flow patterns generated by oblate medusan jellyfish: field meas- urements and laboratory analyses. J Exp Biol 208: $1257-1265$

*Dabiri JO, Colin SP, Katija K, Costello JH (2010) A wakebased correlate of swimming performance and foraging behavior in seven co-occurring jellyfish species. J Exp Biol 213:1217-1225

* Dawson MN, Gupta AS, England MH (2005) Coupled biophysical global ocean model and molecular genetic analyses identify multiple introductions of cryptogenic species. Proc Natl Acad Sci USA 102:11968-11973

Dong H, Bozkurttas M, Mittal R, Madden P, Lauder GV (2010) Computational modelling and analysis of the hydrodynamics of a highly deformable fish pectoral fin. J Fluid Mech 645:345-373

Fancett M (1988) Diet and prey selectivity of scyphomedusae from Port Phillip Bay, Australia. Mar Biol 98: 503-509

* Ford MD, Costello JH, Heidelberg KB, Purcell JE (1997) Swimming and feeding by the scyphomedusa Chrysaora quinquecirrha. Mar Biol 129:355-362

Gemmell BJ, Buskey EJ (2011) The transition from nauplii to copepodites: susceptibility of developing copepods to fish predators. J Plankton Res 33:1773-1777

Gemmell BJ, Troolin DR, Costello JH, Colin SP, Satterlie RA (2015) Control of vortex rings for manoeuvrability. J R Soc Interface 12:20150389

Graham WM, Kroutil RM (2001) Size-based prey selectivity and dietary shifts in the jellyfish, Aurelia aurita. J Plankton Res 23:67-74

* Graham WM, Gelcich S, Robinson KL, Duarte CM and others (2014) Linking human well-being and jellyfish: ecosystem services, impacts, and societal responses. Front Ecol Environ 12:515-523

Hansson LJ (2006) A method for in situ estimation of prey selectivity and predation rate in large plankton, exemplified with the jellyfish Aurelia aurita (L.). J Exp Mar Biol Ecol 328:113-126

Katija K, Beaulieu WT, Regula C, Colin SP, Costello JH, Dabiri JO (2011) Quantification of flows generated by the hydromedusa Aequorea victoria: a Lagrangian coherent structure analysis. Mar Ecol Prog Ser 435:111-123

* Larson RJ (1991) Diet, prey selection and daily ration of Stomolophus meleagris, a filter-feeding scyphomedusa from the NE Gulf of Mexico. Estuar Coast Shelf Sci 32: 511-525

Madin L (1988) Feeding behavior of tentaculate predators: in situ observations and a conceptual model. Bull Mar Sci 43:413-429

Matsakis S, Conover RJ (1991) Abundance and feeding of medusae and their potential impact as predators on other zooplankton in Bedford Basin (Nova Scotia, Canada) during spring. Can J Fish Aquat Sci 48:1419-1430

* Nagata RM, Morandini AC, Colin SP, Migotto AE, Costello JH (2016) Transitions in morphologies, fluid regimes, and feeding mechanism during development of the medusa Lynchnorhiza lucerna. Mar Ecol Prog Ser 557:145-159

O'Brien WJ, Slade NA, Vinyard GL (1976) Apparent size as the determinant of prey selection by bluegill sunfish (Lepomis macrochirus). Ecology 57:1304-1310

*Peach MB, Pitt KA (2005) Morphology of the nematocysts of the medusae of two scyphozoans, Catostylus mosaicus and Phyllorhiza punctata (Rhizostomeae): implications for capture of prey. Invertebr Biol 124:98-108

* Peng J, Dabiri JO (2008) The 'upstream wake' of swimming and flying animals and its correlation with propulsive 
efficiency. J Exp Biol 211:2669-2677

Pierce J (2005) A system for mass culture of upside-down jellyfish Cassiopea spp. as a potential food item for medusivores in captivity. Int Zoo Yearb 39:62-69

Pitt KA, Duarte CM, Lucas CH, Sutherland KR and others (2013) Jellyfish body plans provide allometric advantages beyond low carbon content. PLOS ONE 8:e72683

Purcell JE (1992) Effects of predation by the scyphomedusan Chrysaora quinquecirrha on zooplankton populations in Chesapeake Bay, USA. Mar Ecol Prog Ser 87:65-76

Purcell JE, Arai MN (2001) Interactions of pelagic cnidarians and ctenophores with fish: a review. Hydrobiologia 451: 27-44

Purcell J, Decker M (2005) Effects of climate on relative predation by scyphomedusae and ctenophores on copepods in Chesapeake Bay during 1987-2000. Limnol Oceanogr 50:376-387

Purcell JE, Grover JJ (1990) Predation and food limitation as causes of mortality in larval herring at a spawning ground in British Columbia. Mar Ecol Prog Ser 59:55-61

Purcell JE, Sturdevant MV (2001) Prey selection and dietary overlap among zooplanktivorous jellyfish and juvenile fishes in Prince William Sound, Alaska. Mar Ecol Prog Ser 210:67-83

Purcell JE, Uye S, Lo WT (2007) Anthropogenic causes of jellyfish blooms and their direct consequences for humans: a review. Mar Ecol Prog Ser 350:153-174

Richardson AJ, Bakun A, Hays GC, Gibbons MJ (2009) The jellyfish joyride: causes, consequences and management responses to a more gelatinous future. Trends Ecol Evol $24: 312-322$

Santhanakrishnan A, Dollinger M, Hamlet CL, Colin SP, Miller LA (2012) Flow structure and transport characteristics of feeding and exchange currents generated by upside-down Cassiopea jellyfish. J Exp Biol 215:2369-2381

Editorial responsibility: Shin-ichi Uye,

Higashi-Hiroshima, Japan
Stoecker DK, Michaels AE, Davis LH (1987) Grazing by the jellyfish, Aurelia aurita, on microzooplankton. J Plankton Res 9:901-915

Suchman CL, Sullivan BK (1998) Vulnerability of the copepod Acartia tonsa to predation by the scyphomedusa Chrysaora quinquecirrha: effect of prey size and behavior. Mar Biol 132:237-245

Suchman CL, Sullivan BK (2000) Effect of prey size on vulnerability of copepods to predation by the scyphomedusae Aurelia aurita and Cyanea sp. J Plankton Res 22:2289-2306

Suchman CL, Daly EA, Keister JE, Peterson WT, Brodeur RD (2008) Feeding patterns and predation potential of scyphomedusae in a highly productive upwelling region. Mar Ecol Prog Ser 358:161-172

* Sullivan B, Garcia J, Klein-MacPhee G (1994) Prey selection by the scyphomedusan predator Aurelia aurita. Mar Biol 121:335-341

Swift MC (1981) Chaoborus prey capture efficiency in the light and dark. Limnol Oceanogr 26:461-466

* Titelman J, Hansson LJ (2006) Feeding rates of the jellyfish Aurelia aurita on fish larvae. Mar Biol 149:297-306

* Utne-Palm AC, Salvanes AG, Currie B, Kaartvedt S and others (2010) Trophic structure and community stability in an overfished ecosystem. Science 329:333-336

Uye S (2014) The giant jellyfish Nemopilema nomurai in East Asian marginal seas. In: Pitt KA, Lucas CH (eds) Jellyfish blooms. Springer, Dordrecht, p 185-205

Waggett R, Costello JH (1999) Capture mechanisms used by the lobate ctenophore, Mnemiopsis leidyi, preying on the copepod Acartia tonsa. J Plankton Res 21:2037-2052

Weil R (1934) Contribution à l'étude des Cnidaries et leurs nématocystes. I. Recherches sur les nematocysts. Morphologie-physiologie-développement. Trav Stat Zool Wimereux 10:1-347

Submitted: November 14, 2017; Accepted: March 6, 2018 Proofs received from author(s): May 7, 2018 